\title{
MARIA MALDITA: A FALÊNCIA DA CIVILIDADE EM "MARIA", DE CONCEIÇÃO EVARISTO
}

\author{
Damned Maria: The failure of civility in "Maria", by Conceição Evaristo
}

\author{
Camila Savegnago \\ https://orcid.org/0000-0003-3430-438X \\ Vera Lúcia Lenz Vianna \\ https://orcid.org/0000-0002-2020-3820 \\ Universidade Federal de Santa Maria, Programa de Pós-Graduação em Letras, Santa Maria, \\ RS, Brasil.97105-900 - ppgletras@ufsm.br
}

Resumo: O objetivo deste trabalho é tecer algumas considerações sobre as temáticas da identidade, da alteridade e da civilidade no conto "Maria", de Conceição Evaristo, publicado no livro Olhos d'água (2014). A análise pretende responder de que modo, e em que medida, a constituição identitária de Maria e a sua alteridade, configurada na relação com os outros que a cercam em um ambiente público, como o ônibus, contribuem para a violência a que se vê exposta. Do mesmo modo, o esvaziamento da civilidade, nas sociedades como um todo, é mais um fator que discutimos no artigo, pois sua ausência promove a hostilidade e desestabiliza as relações de afeto que podem humanizar a convivência entre indivíduos. Além disso, propomos uma reflexão sobre a alteridade na sociedade contemporânea, onde as relações são mais fluidas, as redes de afeto mais frágeis, a solidão e a incomunicabilidade, por vezes, uma constante, o que acaba por resultar na falência da civilidade.

Palavras-chave: Identidade. Alteridade. Civilidade. Mulher.

Abstract: This paper has the objective of drawing some considerations about certain aspects regarding problems of identity, otherness and civility which constitute the main themes in the short story "Maria", by Conceição Evaristo, published in the book Olhos d'Água (2014). In this way, what we intend to analyze is how and to what extent Maria's identity and her otherness set in relation to other people who surround her in a public environment, in this case, a bus, contribute to the absurd violence which she is exposed to. The absence of civility, is another feature that is highlighted here as it promotes hostility and destabilizes the feeling of solidarity that may humanize the contact among individuals. We propose a reflection about otherness in the contemporaneity, where relationships are more fluid, emotional networks are more fragile, solitude and incommunicability are a constant sometimes; and, as a result, all those aspects promote the failure of our civility.

Keywords: Identity. Otherness. Civility. Woman.

Maria. Um nome feminino popular no Brasil e que nos faz lembrar de imediato outras

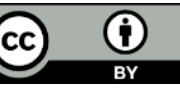

Esta obra está licenciada sob uma Creative Commons - Atribuição 4.0 
tantas 'Marias': abençoadas, amaldiçoadas, anônimas ou célebres. Maria é o nome que dá título a um conto de Conceição Evaristo, publicado em 2014, no livro Olhos d'água. No conto, Maria é uma mulher negra, empregada doméstica, que, após mais um dia de trabalho, ao retornar para casa de ônibus, é vítima de um de linchamento, cometido por outros passageiros do coletivo. $\mathrm{O}$ protagonismo feminino e a violência cotidiana a que as mulheres estão expostas costumam ser temáticas recorrentes na obra da escritora mineira Conceição Evaristo, que faz da sua escrita um espaço de emergência de vozes subalternas e periféricas. Ao produzir uma literatura de autoria feminina e negra de qualidade indiscutível, ela paulatinamente conquista seu lugar de relevância na literatura brasileira e nos estudos literários dentro da academia. Sobre sua escrita, a autora afirma:

\begin{abstract}
Mas digo sempre: creio que a gênese de minha escrita está no acúmulo de tudo que ouvi desde a infância. $\mathrm{O}$ acúmulo das palavras, das histórias que habitavam em nossa casa e adjacências [...]. Na origem da minha escrita ouço os gritos, os chamados das vizinhas debruçadas sobre as janelas, ou nos vãos das portas contando em voz alta uma para outras as suas mazelas, assim como as suas alegrias. Como ouvi conversas de mulheres! Falar e ouvir entre nós, era talvez a única defesa, o único remédio que possuíamos. Venho de uma família em que as mulheres, mesmo não estando totalmente livres de uma dominação machista, primeira a dos patrões, depois a dos homens seus familiares, raramente se permitiam fragilizar. Como "cabeça" da família, elas construíam um mundo próprio, muitas vezes distantes e independentes de seus homens e mormente para apoiá-los depois. Talvez por isso tantas personagens femininas em meus poemas e em minhas narrativas? Pergunto sobre isto, não afirmo $^{1}$ (EVARISTO, 2007, p. 19).
\end{abstract}

Ao processo de escrever a existência com base em vivências, experiências e histórias que ouvia desde criança, Conceição Evaristo denominou "escrevivência". Escrever a partir da perspectiva de uma parcela específica da população brasileira, que compartilha medos, dores, desejos, histórias, caracteriza o projeto literário da autora. Nesse contexto, a literatura vai além da sua função estética, atingindo uma função social e ética: "Foi daí, talvez, que eu descobri a função, a urgência, a dor, a necessidade e a esperança da escrita. É preciso comprometer a vida com a escrita ou é o inverso? Comprometer a escrita com a vida?" (EVARISTO, 2007, p. 17). Em "Maria", valores humanos essenciais como direito à vida, solidariedade, respeito, parecem ruir. Ao final do conto, resta um profundo sentimento de desamparo perante uma sociedade em que as relações estão cada vez mais fluidas, a comunicação falha, a empatia e o afeto comprometidos. Uma sociedade em que indivíduos nem sempre conseguem controlar sua crueldade, em que atos de barbárie tornam-se corriqueiros, banalizados e naturalizados, de modo que se observa uma sensível falha no exercício da civilidade. Nesse sentido, Conceição Evaristo representa o olhar de alguém que está legitimado, a partir do seu lugar de fala, de mulher negra periférica, a ficcionalizar histórias de um determinado grupo social e dar voz

\footnotetext{
${ }^{1}$ Texto apresentado na Mesa de Escritoras Afro-brasileiras, no XI Seminário Nacional Mulher e Literatura/II Seminário Internacional Mulher e Literatura, Rio de Janeiro, 2005. Disponível em: http://nossaescrevivencia.blogspot.com/2012/08/da-grafia-desenho-de-minha-mae-um-dos.html. Acesso em: $16 / 03 / 2019$.
} 
àqueles que costumam ser silenciados na literatura, como as muitas 'Marias' brasileiras que têm suas vozes cerceadas diariamente por conta da violência e que, muitas vezes, acabam se tornando apenas mais um número em estatísticas de criminalidade.

Ao pensar sobre alguns dos traços que constituem o perfil da personagem Maria no conto, parece relevante realizar uma pequena consideração acerca do par identidade/alteridade. Landowsky (2002) sinaliza, de forma inicial, a multiplicidade de fatores que podem definir a identidade de um sujeito: o que ele é, o que ele parece ser, as escolhas que faz, as relações que estabelece com outros e o sentido que dá a sua existência, são alguns pontos que contribuem para a construção de uma identidade individual e coletiva. Desse modo, construir-se como sujeito: "É tentar captar o mínimo de coerência que dá sentido e unidade ao devir que faz com que cada um seja, individual ou coletivamente, o que é." (LANDOWSKI, 2002, p. 26). O reconhecimento da alteridade é fundamental para a busca de uma identidade própria, pois esta se constrói também por meio das relações de oposição que se estabelecem com o outro, pelo reconhecimento de diferenças, pelo reforço de estereótipos. Conforme Landowski (2002, p. 4):

O que dá forma a minha própria identidade não é só a maneira pela qual, reflexivamente, eu me defino (ou tento me definir) em relação à imagem que outrem me envia de mim mesmo; é também a maneira pela qual, transitivamente, objetivo a alteridade do outro atribuindo um conteúdo específico à diferença que me separa dele. Assim, quer a encaremos no plano da vivência individual ou - como será o caso aqui - da consciência coletiva, a emergência do sentimento de 'identidade' parece passar necessariamente pela intermediação de uma 'alteridade' a ser construída.

No conto "Maria", o processo de reconhecimento identitário, por meio da "intermediação de uma 'alteridade' a ser construída", fica evidente e adquire significância para a compreensão do destino da protagonista. A construção da personagem principal se dá por meio de três perspectivas, em outras palavras, são três olhares que se cruzam e constroem o seu perfil: o do narrador, o da própria personagem e o dos outros passageiros do ônibus. Pelas palavras do narrador, sabe-se que Maria é uma empregada doméstica, de classe social baixa, com pouco poder aquisitivo, pois se preocupa com o aumento constante da passagem de ônibus e demonstra grande alegria não só por ter recebido uma gorjeta que servirá para comprar remédios e 'toddy' para os filhos, mas por levar frutas para casa, especialmente melão, uma vez que os filhos nunca o haviam provado. Através de uma conversa com o seu 'ex-homem', pai de seu primeiro filho, sabemos que Maria tem três filhos, todos menores de 11 anos, mas não é casada e cuida de todos sozinha. Além de mulher e pobre, Maria é negra. Tem-se acesso a essa informação pela voz de outros passageiros que se dirigem a ela de forma agressiva, acusando-a de ser cúmplice dos bandidos que assaltam o ônibus: "Negra safada, vai ver que estava de coleio com os dois", "Olha só, a negra ainda é atrevida" (EVARISTO, 2018, p. 43). Com isso, nota-se, no sujeito Maria, a intersecção de várias categorias identitárias como raça, sexo, classe social e econômica, todas reforçando sua condição de marginalidade e vulnerabilidade.

Landowski (2002) discute as relações de alteridade usando como pontos de referência dois polos: o Eu/Nós, representativo do grupo hegemônico, homogêneo e conservador, e o 
Ele/Outro(s), representativo do grupo daqueles que são segregados ou excluídos, tendo em vista a existência de alguma diferença que não pode ser aceita no grupo dominante, a fim de evitar sua desestabilização e uma possível perda da posição de referência. Nesse sentido, é possível afirmar que Maria ocupa uma posição de marginalidade em relação ao que se considera o grupo principal, representado, no conto, pela figura da patroa. Ela e os outros passageiros do ônibus são os que precisam usar transporte público, muitas vezes, em atraso e lotado, e ainda estão expostos à criminalidade, especialmente, assaltos à mão armada. Ainda de acordo com o teórico, é o próprio grupo dominante que produz as diferenças, as desigualdades, as distâncias entre eles:

essa heterogeneidade atual ou potencial à qual o grupo se opõe com todas as forças, é ao mesmo tempo ele que, sob muitos aspectos, a faz existir, e isso, além do mais, em dois níveis e de duas maneiras diferentes, mas que cumulam seus efeitos: ao mesmo tempo em superfície, produzindo socialmente disparidades de toda a ordem e, num nível mais profundo, construindo sem cessar, semioticamente, a 'diferença' (LANDOWSKI, 2002, p. 11).

Essas disparidades são responsáveis pela sensação de tensão constantemente sentida nas relações sociais, num ambiente urbano, por exemplo, onde predomina a diversidade entre os sujeitos ou entre os grupos, ou ainda dos sujeitos com o seu próprio grupo; são pessoas das mais diversas origens, com os mais variados desejos e com as mais diferentes vivências tendo de conviver diariamente. $\mathrm{Na}$ produção da alteridade, as fronteiras não são naturais, mas sim demarcações construídas em função do ponto de vista que se adota como dominante (LANDOWSKI, 2002, p. 3). Nesse processo, primeiro as diferenças são constatadas para, num segundo momento, tornarem-se significantes, em termos biológicos, genéticos, econômicos, culturais. Isso porque, mesmo que todos sejam sujeitos em si mesmos, eles pertencem a categorias particulares (estatutos, papéis, posições) que acabam por interdefinir ou diferenciar uns dos outros:

Por que, mesmo que todo mundo seja em princípio "sujeito" do mesmo modo, cada um se apresenta na realidade, tanto para outrem como para si mesmo, como pertencente a 'sua'categoria sócio-profissional, a 'seu' meio étnico- ou cultural, a 'seu'grupo linguístico ou confessional - e, é claro, além do mais, a sua faixa etária, a sua geração, a seu sexo (LANDOWSKI, 2002, p. 32).

Desse modo, ainda que Maria e os outros passageiros do ônibus pertençam ao mesmo grupo, o marginalizado, em função especialmente de sua condição econômica e classe social, ficam evidentes os traços diferenciais no seu próprio interior. A união entre esses sujeitos periféricos, com o intuito de excluir a ameaça que a figura de Maria representa, é temporária e irracional. Tem-se, assim, os que assumem diferentes posições, os que se apresentam como um tipo mais acabado, outros com mais falhas, os que estão mais ou menos à margem do grupo do qual fazem parte, gerando com isso uma multiplicidade de possíveis combinações e, consequentemente, de diferentes imagens de sujeitos. Há duas dicotomias principais que se estabelecem dentro do grupo que considero aqui como marginalizado e que está ocupando o 
espaço do transporte público. A primeira diz respeito aos passageiros que estão ali para se locomover e aos que estão ali para cometer um crime, no caso, os dois assaltantes; a segunda se dá, em um momento posterior, entre a personagem Maria e alguns passageiros homens, que a agridem. Habitar, dividir um espaço público, pressupõe a coexistência com modos de vida e lugares de proveniência (origem) diversos, o que pode e deve implicar o ressurgimento de práticas de enfrentamento com o fim último de preservação. O próprio grupo, por vezes, assume a postura de segregar, perseguir o outro, a pretexto de desvio, periculosidade, inadaptação ao ambiente ou ameaça à própria vida.

No contexto do conto "Maria", os passageiros não podem reagir ao assalto que sofrem no ônibus, pois isso representaria um risco a sua própria vida. Porém, após o incidente, talvez por se sentirem exaustos e com raiva da violência cotidiana a que são expostos, ou talvez por uma simples necessidade de exercer seu poder sobre alguém que consideram mais fraco, redimindose, assim, de sua covardia, acabam se voltando contra Maria. Eles encontram nela uma espécie de bode expiatório e, em certo sentido, de expiação para a violência que haviam sofrido. A origem da violência verbal e física direcionada a Maria está no seu encontro casual e rápido com um homem no ônibus. Ao entrar no transporte público, ela acaba se deparando com alguém a quem refere como seu 'ex-homem', o pai de seu filho mais velho de 11 anos, e de quem ela afirma sentir saudade e ainda amar: "Ela reconheceu o homem. Quanto tempo, que saudades! Como era difícil continuar a vida sem ele" (EVARISTO, 2018, p. 42). De repente, durante a conversa, o homem se ergue e anuncia o assalto juntamente com um comparsa. Maria sente medo, já que é a primeira vez que vivencia essa situação, e a sua grande preocupação é com os filhos: "Maria estava com muito medo. Não dos assaltantes. Não da morte. Sim da vida. Tinha três filhos" (EVARISTO, 2018, p. 43).

No entanto, os assaltantes passam por ela e não pedem nada:

Se fossem outros os assaltantes? Ela teria para dar uma sacola de frutas, um osso de pernil e uma gorjeta de mil cruzeiros. Não tinha relógio algum no braço. Nas mãos nenhum anel ou aliança. Aliás, nas mãos tinha sim! Tinha um profundo corte feito com faca-laser que parecia cortar até a vida (EVARISTO, 2018, p. 43).

Maria se sente aliviada pelo assalto ter terminado e desesperada por ver seu excompanheiro indo embora; esses sentimentos, contudo, duram pouco, pois algumas vozes masculinas logo começam a se insurgir no fundo do ônibus, acusando-a de ser cúmplice dos assaltantes, uma vez que conversou com um deles e nada lhe foi exigido durante a ação criminosa. As vozes acusam-na de conhecer os assaltantes, de que devia estar de conluio com eles, de modo que acabam por compor a representação de um coletivo que, ao se sentir ameaçado, reage de forma violenta. Nota-se que predomina a concepção do senso comum, pois as acusações hipotéticas começam a ser repetidas e se tornam algo tomado como verdadeiro, inquestionável:

a coexistência entre pessoas ou coletividades se insere no âmbito de situações de fato que têm toda a aparência de estados de coisas baseados na natureza ou 
herdados da história e, por conseguinte, de realidades 'incontornáveis'. Assim, sem que praticamente eu possa fazer nada contra isso, minha língua, meu sotaque, minha nacionalidade, minha educação, minhas ideias, eventualmente minha religião - ou pior, meu ateísmo - e, em geral, todos os meus modos de ser, adquiridos em contato com o meio em que vivo, fazem por si sós de mim o que pareço, isto é, pelo menos para os outros, o que eu sou (LANDOWSKI, 2002, p. 33).

A personagem Maria não tem controle sobre a imagem que os outros constroem sobre ela, sobre os rótulos que lhe são atribuídos: "puta safada", "puta", "negra safada"; é como se ela estivesse predisposta a sofrer essa violência verbal pela intersecção de sua condição de mulher, negra, pobre, no sentido de que cada uma dessas características funcionaria como um reforço da outra. Assim, ela seria, no grupo dos marginalizados, alguém que está ainda mais à margem e que sequer merece ter voz.

Da cena de abertura, onde a figura simples de uma mulher e pequenos relatos sobre seu cotidiano de pobreza e dignidade são oferecidos, a narrativa adquire um rumo insuspeitado para o leitor que não está familiarizado com a escrita de Conceição Evaristo. As vozes com palavras ofensivas dirigidas à personagem feminina tornam-se agressões físicas: "Olha só, a negra ainda é atrevida, disse o homem, lascando um tapa no rosto da mulher. Alguém gritou: Lincha! Lincha! Lincha!... Uns passageiros desceram e outros voaram em direção a Maria" (EVARISTO, 2018, p. 44). Tais palavras raivosas se sobrepõem tanto à tentativa de manifestação de inocência da própria Maria, quanto a do motorista do ônibus que busca interferir, afirmando que conhece a mulher, que ela é trabalhadora e luta para sustentar os filhos: "Calma, pessoal! Que loucura é esta? Eu conheço esta mulher de vista. Todos os dias, mais ou menos neste horário, ela toma o ônibus comigo. Está vindo do trabalho, da luta para sustentar os filhos..." (EVARISTO, 2018, p. 44).

Maria, anônima e inapreensível aos olhos do centro, torna-se, abruptamente, maldita e alvo de um gesto de covardia e barbárie. As agressões tomam proporções dramáticas e, sem ter chance de entender porque havia se tornado culpada, a personagem sofre um linchamento praticado por alguns passageiros do ônibus: "Maria punha sangue pela boca, pelo nariz e pelos ouvidos. A sacola havia arrebentado e as frutas rolavam pelo chão. Será que os meninos gostam de melão?" (EVARISTO, 2018, p. 44). Atordoada pelo ataque do qual é vítima, Maria só pensa nos filhos que precisam dela e nos mantimentos que pudera comprar com dificuldade.

A narrativa acaba brutalmente. Ao final, resta o corpo imóvel da mulher no chão do ônibus. Escrito com um realismo sem maquiagem, o sentimento de espanto e desamparo da personagem é sentido pelo leitor, que se vê refém de uma narrativa caracterizada pelo tom cruel e pela habilidade de Conceição Evaristo em surpreender com suas histórias. Quase todos os contos compilados em Olhos d'água apresentam a violência como sentimento propulsor da estética da contista. A impulsividade imprevisível e descontrolada, exposta em uma narrativa tão breve como "Maria", é um convite ao exercício das mais variadas reflexões. Como nossa humanidade se desgastou ao longo do tempo? De que modo a solidariedade e a civilidade podem ser resgatadas? Até que ponto o investimento em um 'nós' hipostasiado em detrimento 
dos 'outros' pode ser mantido? Essas e outras tantas perguntas sobre as relações humanas são oferecidas pelas "escrevivências" de Conceição Evaristo e conferem uma natureza política e ética ao conjunto de seu trabalho. Contos dessa coletânea, bem como em Insubmissas lágrimas de mulheres (2011) e Ponciá Vicêncio (2003), exibem, invariavelmente, a marca da violência contra a mulher e nos fazem pensar sobre a fragilidade da lei e da civilidade, entre outros aspectos, perante incidentes que barbarizam, cerceiam e silenciam suas vítimas, e que são recorrentes em tantos e diversos contextos. Ao discorrer sobre os impulsos e instintos primitivos que conduzem a atos de violência, Gilles Lipovetsky, em A era do vazio, destaca que:

A impulsividade extrema e desenfreada dos homens, correlativa das sociedades que precedem o estado absolutista, foi substituída por uma regulamentação de comportamentos, pelo autocontrole do indivíduo, enfim, pelo processo de civilização que acompanha a pacificação do território realizada pelo Estado moderno (LIPOVETSKY, 2005, p. 161).

Entretanto, esse autocontrole do indivíduo sobre suas ações, desenvolvido junto ao estabelecimento dos estados modernos, não adquiriu, até o momento, solidez. O processo de desestabilização ou colapso na modernidade tardia ou pós-modernidade, principalmente, pelo princípio do viver tudo aqui e agora, de modo que: "A violência hard, desesperada, sem projeto, sem consistência, é a imagem de um tempo sem futuro que valoriza o "tudo, agora", (LIPOVETSKY, 2005, p. 179). A desestabilização individual motivada pela dificuldade em lidar com as frustrações, com as perdas, estimulam o crescimento de situações que envolvem violência, assim como a multiplicação de crimes cometidos por pequenos deslizes ou por 'quase nada'; a exasperação, 'os nervos' parecem comandar a dinâmica do grupo que está no ônibus que, movido pelo desejo de punir, de revidar com urgência a ação criminosa de que foram vítimas, se voltam contra Maria.

Conceição Evaristo escreve sobre a violência perpetuada contra uma mulher, em especial, uma mulher negra. Sua literatura está vinculada ao legado histórico de escravização da comunidade negra que confere especificidade à temática de sua produção. Sem esquecer a etnia de Maria e a problemática inerente a essa questão, esta análise acentua a questão da escassez do sentimento de civilidade, como uma forma de promoção da 'violência hard, desencantanda' da qual Lipovetsky (2005, p. 188) discorre. Difícil escapar desse sentimento que irrompe sem aviso e que demanda o exercício consciente de civilidade como dinâmica de oposição. Em "Maria", a agressão desmedida se manifesta e a civilidade desaparece. O encontro acidental de Maria com seu ex-companheiro, no ônibus, é determinante para a violência que sofre. Seria possível dizer que seu deslize, nessas circunstâncias, teria sido conversar com o pai de seu filho mais velho e coincidentemente o assaltante: "Ela não conhecia assaltante algum. Conhecia o pai do seu primeiro filho. Conhecia o homem que tinha sido dela e que ela ainda amava tanto" (EVARISTO, 2018, p. 43). Nesse sentido, nota-se o exercício da violência por ela mesma, pois ela não se dá pela defesa da honra ou vingança, como nas sociedades mais primitivas, uma vez que Maria não participou da ação dos assaltantes. A decisão de linchar Maria foi tomada com base em uma simples suspeita, não houve espaço para o diálogo, para o respeito, nem para a 
reflexão, culminando num ato de barbárie. Somada às características de identidade, alteridade, relativas à personagem principal, aos outros passageiros do ônibus, bem como ao grupo no qual ela se insere, cabe ainda uma discussão acerca do espaço onde essa história se desenrola, pois ele também parece contribuir significativamente para o desfecho trágico.

Em a Modernidade Líquida (2001), Bauman discute, no capítulo três, as categorias de tempo e espaço na modernidade, verificando de que modo as relações humanas se configuram em diferentes tempos e espaços, além de resgatar e ampliar a discussão sobre o conceito de civilidade, abordado por Richard Senett. Bauman parte da concepção moderna de comunidade como um local constantemente vigiado por seus membros que trata os 'estranhos' com desconfiança. Nesse contexto, há os que são punidos, os que são expulsos, os que são impedidos de entrar. Há, portanto, no cerne dessas comunidades, um profundo medo do diferente, tomado como ameaça, e uma crença na conspiração dos outros contra o nós do grupo de referência, o que, por sua vez, alimenta o instinto constante de proteção do grupo, muitas vezes, justificado pelo alto índice de violência das cidades. O espaço urbano, assim, é visto como um “" assentamento humano em que os estranhos têm chance de se encontrar'. Isso significa que estranhos têm chance de se encontrar em sua condição de estranhos, saindo como estranhos do encontro casual que termina de maneira tão abrupta quanto começou" (BAUMAN, 2001, p. 111). Para Bauman, essas circunstâncias parecem marcar mais um desencontro do que um encontro propriamente dito. Isso porque esse cruzamento de estranhos é um evento do aqui e do agora, ele existe enquanto dura, pois não há um passado a ser compartilhado, nem retomado, tampouco se espera que aja um futuro, esse encontro representaria, assim, uma história para não ser continuada. Tal concepção é bastante desalentadora, pois se entende que "no momento do encontro não há espaço para tentativa e erro, nem aprendizado a partir dos erros ou expectativa de outra oportunidade" (BAUMAN, 2001, p. 111). Os únicos possíveis pontos de apoio que podem tornar esse encontro, entre estranhos, mais amigável são: aparência, palavras e gestos em comum, ou que geram identificação entre os indivíduos. Nesse sentido, o convívio em sociedade, especialmente a vida urbana, exige um conjunto de habilidades que podem ser agrupadas sob o conceito de civilidade:

A atividade que protege as pessoas umas das outras, permitindo, contudo, que possam estar juntas. Usar uma máscara é a essência da civilidade. As máscaras permitem a sociabilidade pura, distante das circunstâncias do poder, do mal estar e dos sentimentos privados das pessoas que as usam. A civilidade tem como objetivo proteger os outros de serem sobrecarregados com nosso peso (SENETT apud BAUMAN, 2001, p. 112).

Espera-se que a civilidade seja aprendida e exercitada constantemente, para que, assim, ela seja capaz de proteger os indivíduos uns dos outros, seja na tentativa de evitar agressões psicológicas, verbais, físicas, ou, até mesmo, no intuito de evitar situações constrangedoras ou inconvenientes. Vista sob esse ângulo, a civilidade:

como a linguagem, não pode ser 'privada'. Antes de se tornar a arte individualmente aprendida e privadamente praticada, a civilidade deve ser 
uma característica da situação social. É o entorno urbano que deve ser 'civil', a fim de que seus habitantes possam aprender as difíceis habilidades da civilidade (BAUMAN, 2001, p. 112).

Desse modo, o meio urbano deve disponibilizar espaços que estimulem o compartilhamento de vivências, experiências, prezar pelo bem comum de seus habitantes, impedindo que vontades individuais predominem sobre os desejos da maioria. Por isso, do uso da máscara da civilidade dependem a participação e a integração verdadeira dos sujeitos no ambiente social e público ao qual pertencem. Ao analisar essas reflexões de Bauman sobre o espaço e as relações sociais entre estranhos, nota-se que o exercício da civilidade falhou irremediavelmente na história de Maria.

Toda a história do conto "Maria" se passa em um meio urbano e em um espaço público; lugares, portanto, propícios ao encontro cotidiano entre estranhos. No ponto e, depois, dentro do ônibus, Maria convive com pessoas estranhas, com as quais não tem uma história passada em comum para ser lembrada nem uma expectativa de relação futura, exceto com um dos assaltantes, com o qual já teve uma relação amorosa, e com o motorista, que diz conhecê-la porque ela sempre usa o ônibus naquele horário. A situação do assalto no ônibus despertou o medo e desencadeou o sentimento de ameaça nos passageiros, de modo que eles, enquanto grupo, sentiram-se compelidos a reagir violentamente, a fim de eliminar o que eles ainda estavam considerando uma ameaça: a mulher que conversou com o assaltante e não foi roubada por ele.

O fato de a agressão ter ocorrido em um ônibus e não na rua, por exemplo, também é significativo para a compreensão do trágico acontecimento. Pois, segundo Bauman, espaços como o transporte público, aeroportos, autoestradas, quartos de hotel, podem ser considerados como não lugares. Os indivíduos não estão nesses locais com o intuito de estabelecer relações com os outros, pois são lugares de passagem, onde a hospitalidade e a preocupação com o outro praticamente inexistem, afastando-se assim do modelo de espaço civil: "é um espaço destituído das expressões simbólicas de identidade, relações e história” (BAUMAN, 2001, p. 120). À medida que se multiplicam esses não lugares, diminui o aprendizado da civilidade, pois eles dispensam a interação, a comunicação, a construção de alguma rede de afeto. Bauman ressalta que nos locais onde os hábitos da "civilidade estiverem ausentes ou forem pouco desenvolvidos" (2001, p. 119), o estado, enquanto responsável pela segurança de sua população, precisa intervir ou estar presente de modo mais efetivo. $\mathrm{O}$ ideal seria que as pessoas, independente de onde estivessem e com quem estivessem, respeitassem as diferenças e interagissem, sobretudo, sem ferir o outro. Verifica-se, no entanto, com relação à personagem Maria, que não há nem o exercício individual nem coletivo da civilidade no espaço público onde se encontra. Além disso, por ser um local de passagem, o poder do governo, representado pela autoridade policial, responsável por garantir a integridade dos sujeitos, somente aparece e adentra no veículo quando ele já está parado e vazio, com o corpo de Maria inerte no chão.

Portanto, esses não lugares, pelas suas características peculiares, são propícios à geração de atos de violência: 
O perigo representado pela companhia de estranhos é uma clássica profecia autocumprida. Torna-se cada vez mais fácil misturar a visão dos estranhos com os medos difusos da insegurança o que no começo era uma mera suposição torna-se uma verdade comprovada, para acabar como algo evidente (BAUMAN, 2001, p. 124).

Não há dúvida de que o grupo de pessoas, estranhas entre si, que ocupam o espaço do ônibus, compartilha o mesmo sentimento de insegurança gerado pela violência nas grandes cidades. E são esses medos, transformados em raiva e revolta, que acabam direcionados para uma pessoa específica que, naquele aqui-agora, era o outro, era o estranho, ligado aos assaltantes. Não há de fato uma interação entre os sujeitos naquele local; alguns falam, mas não há um diálogo efetivo, parece que ninguém ouve o que o outro diz. As vozes de defesa de um passageiro em relação à mulher, as vozes de Maria e do motorista, não são consideradas; o grande grupo se organiza por um objetivo maior que é a defesa de seus interesses comuns: eliminar a ameaça do ônibus, sem que para isso se proceda, de fato, à apuração do que houve. A verdade não é importante, privilegia-se o parecer e não o ser. Nota-se, com isso, o quanto os laços sociais estão fluidos, inconstantes, e a rede de afetos frágil, pois é possível passar pelo outro, esmagá-lo, mas sequer saber quem é esse sujeito.

O encontro desse grupo de estranhos no ônibus é o mais claro exemplo de um ato de falha dos hábitos de civilidade e da instalação da barbárie. Isso porque os passageiros, os que cometem o ato de violência e os que simplesmente ignoram a violência cometida, passaram por Maria, provocaram sua morte, e saíram do ônibus como entraram: não tinham um passado para compartilhar com ela, e não terão um futuro. Pode-se dizer que saíram convictos de que fizeram o que era necessário para a sua segurança e a do grupo ao qual pertencem, já que alguém precisava pagar pela violência que haviam sofrido, de preferência, alguém mais vulnerável, sobre o qual poderiam exercer sua força, com a certeza de serem bem sucedidos. Com isso, as características de identidade da personagem, as relações de alteridade que estabelece, o espaço onde as ações ocorrem, reforçam-se mutuamente no sentido de corroborar o fim trágico da personagem. Pois, se ela não fosse uma mulher negra, se não estivesse sozinha naquele local, se estivesse em outro lugar, se não tivesse conversado com o pai de seu filho, provavelmente seu destino teria sido diferente. Talvez o grupo, mesmo ameaçado, não teria tido a coragem de agir, pelo receio de não ser bem sucedido ou pela possibilidade de ser responsabilizado pelo ato criminoso do assassinato. A impunidade, nesse contexto, é outro fator que reforça a disseminação da violência, já que os indivíduos beneficiam-se, protegidos pelo anonimato, do ato bárbaro cometido em grupo e pela presença quase anônima no não lugar do transporte público.

Além das questões temáticas mencionadas acerca do conto lido, também é interessante observar como a escritora Conceição Evaristo põe a sua escrita a serviço da discussão de questões éticas na nossa sociedade. Ela prioriza em sua ficção a representação de personagens que vivem à margem da sociedade, personagens que têm suas vozes silenciadas e estão expostas diariamente às mais diversas formas de violência; ela apresenta um mundo periférico e desconhecido para grande parte da sociedade brasileira, retrata também esses não lugares, esses 
lugares vazios que não constam no nosso mapa mental, locais pelos quais passamos, mas não os vemos de fato, ou simplesmente ignoramos sua existência. O estilo de escrita mais direto e mais conciso, que privilegia a narração dos eventos, constitui uma estratégia estética da autora, para reforçar aquilo que pretende contar nas suas ficções.

Nadja Hermann (2005, p. 14), em um estudo sobre ética e estética, afirma que "A emergência da estética aponta que as forças da imaginação, da sensibilidade e das emoções teriam maior efetividade para o agir do que a formulação de princípios abstratos e do que qualquer fundamentação teórica da moral". Em outras palavras, a autora acentua a força que a arte possui na determinação do nosso agir moral. A ficção de Conceição Evaristo nos coloca, sem dúvida, diante do estranho, do plural, e faz com que nos deparemos com eventos que atingem diretamente nossa sensibilidade e nossas emoções e problematizam nosso agir moral:

Paralelamente, às críticas desconstrutivistas, a própria experiência científica e estética inicia uma flexibilização de critérios culturais, em que a verdade é relativizada e a subjetividade torna-se cada vez mais descentrada. Os cânones estéticos clássicos passam por transformação, se aguça o processo de autonomia da criação, que favorecem o perspectivismo. A ruptura da unidade e a pluralidade radicalizada, que faz emergir a diferença [...] a valorização da pluralidade existe há muito tempo, mas agora adquiriu um estatuto próprio, pois não se trata apenas de uma especulação abstrata, mas uma determinação da realidade da vida (HERMANN, 2005, p. 25).

No conto "Maria", a autora nos põe ao lado de uma mulher, cansada, machucada, trabalhadora, mas que, mesmo assim, volta para sua casa feliz, após mais um dia de trabalho, pois está levando uma gorjeta e alguns alimentos que sobraram da festa na casa da patroa; que fica contente ao reencontrar seu ex-companheiro, apesar de ele tê-la abandonado e de não ajudar na criação do filho. No cerne da problemática do conto, está a questão da injustiça, pois, ao fim e ao cabo, a morte de Maria origina-se de uma situação de injustiça, de uma pressuposição de culpa e de uma ação violenta e criminosa voltada para um inocente em relação ao assalto cometido no ônibus. A não ser que, para os passageiros do ônibus, o simples contato com um criminoso tornasse o sujeito igualmente um bandido. O que, por sua vez, demanda o debate de questões éticas. Até que ponto um sujeito tem o direito de tirar a vida de outra pessoa, mesmo que se sinta ameaçado? Até que ponto esse sujeito pode agir por iniciativa própria sem possibilitar a defesa do acusado? Vale, na sociedade, a lei do mais forte, de modo que quem tem mais força subjuga e silencia os mais fracos, marginalizados, como mulheres negras e pobres?

Hermann (2005, p. 41) acrescenta ainda sobre o poder subversivo da arte: "A arte, enquanto jogo, contém um elemento que ultrapassa o domínio da reflexão. A obra de arte nos põe diante do estranho, provoca novos questionamentos, solicita uma compreensão para além daquilo que nos é habitual". Em outras palavras, nos desacomoda. Ainda que as máscaras da civilidade comecem a cair, a arte com sua função estética, ética e social continuará nos desafiando e impelindo a reflexões sobre nós e sobre o outro; afinal, é imprescindível lembrar que todos somos sujeitos e que todos somos seres humanos, e que, portanto, o exercício da 
civilidade é vital para o agenciamento de relações sociais mais justas.

\section{Referências}

BAUMAN, Zigmund. Modernidade Líquida. Rio de Janeiro: Jorge Zahar, 2001.

EVARISTO, Conceição. Olhos d'água. Rio de Janeiro: Pallas Mini, 2018.

EVARISTO, Conceição. Ponciá Vicêncio. Belo Horizonte: Maza edições, 2003.

EVARISTO, Conceição. Insubmissas lágrimas de mulheres. Belo Horizonte: Nandyala, 2011.

EVARISTO, Conceição. Da grafia desenho de minha mãe: um dos lugares de nascimento de minha escrita. In: ALEXANDRE, Marcos Antônio (Org). Representações performáticas brasileiras: teorias, práticas e suas interfaces. Belo Horizonte: Mazza Edições, 2007. p. 16-21.

HERMANN, Nadja. Ética e Estética. Porto Alegre: EDIPUCRS, 2005.

LANDOWSKI, Eric. Presenças do outro. São Paulo: Perspectiva, 2002.

LIPOVETSKI, Gilles. A era do vazio: ensaios sobre o individualismo contemporâneo. São Paulo: Manole, 2005.

Camila Savegnago (camilasavegnago@gmail.com) possui Licenciatura em Letras Português e respectivas Literaturas pela Universidade Federal de Santa Maria (UFSM) e Mestrado em Estudos Literários pela mesma instituição. Atualmente, realiza Doutorado em Estudos Literários no Programa de Pós-Graduação em Letras da UFSM, na linha de pesquisa Literatura, Cultura e Interdisciplinaridade. Suas pesquisas priorizam o estudo da Literatura Portuguesa Contemporânea.

Vera Lucia Lenz Vianna (lenzvl@gmail.com) é Professora Associada do Curso de Letras, Universidade Federal de Santa Maria, RS. Mestre em Literatura Anglo-Americana pela Universidade Federal do Rio Grande do Sul e Doutora em Literatura Comparada, pela mesma instituição. Professora bolsista selecionada pela USIA. Local de pesquisa: New School for Social Research, New York, USA. Pertence à linha de pesquisa Literatura,Comparatismo e Crítica Social do PPGLetras da UFSM.

\section{NOTAS DE AUTORIA}

\section{Como citar esse artigo de acordo com as normas da revista}

SAVEGNAGO, Camila; VIANNA, Vera Lucia Lenz. Maria maldita: a falência da civilidade em "Maria", de Conceição Evaristo. Anuário de Literatura, Florianópolis, v. 24, n. 1, p. 101$113,2019$.

\section{Contribuição de autoria}

Camila Savegnago: Concepção do trabalho, coleta e análise dos dados, elaboração do manuscrito, discussão dos resultados e elaboração da conclusão.

Vera Lúcia Lenz Vianna: Concepção do trabalho (orientação), sugestão de referencial teórico, revisão dos resultados e do manuscrito.

\section{Financiamento}


Não se aplica.

Consentimento de uso de imagem

Não se aplica.

Aprovação de comitê de ética em pesquisa

Não se aplica.

Licença de uso

Este artigo está licenciado sob a Licença Creative Commons CC-BY. Com essa licença você pode compartilhar, adaptar, criar para qualquer fim, desde que atribua a autoria da obra.

\section{Histórico}

Recebido em: 31/03/2019

Aprovado em: 20/05/2019

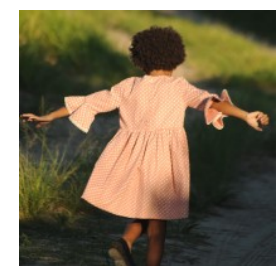

